Adult attention deficit hyperactivity symptoms and psychosis: epidemiological evidence from a population survey in England

Running title: Adult ADHD symptoms and psychosis

Steven Marwaha ${ }^{a, b}$, Andrew Thompson ${ }^{a}$, Paul Bebbington ${ }^{c}$, Swaran. P. Singh ${ }^{a}$, Daniel Freeman $^{\text {, }}$, Catherine Winsper ${ }^{\mathrm{a}}$, Matthew R. Broome ${ }^{\mathrm{a}, \mathrm{d}, \mathrm{e}}$

a Division of Mental Health and Wellbeing,

Warwick Medical School, University of Warwick,

Coventry, CV47AL, UK

${ }^{\mathbf{b}}$ Early intervention service

Swanswell point

Coventry, CV14FH, UK

${ }^{\mathbf{c}}$ Division of Psychiatry,

University College London,

67-73 Riding House St.

London W1W 7EJ, UK

${ }^{\mathbf{d}}$ Department of Psychiatry,

University of Oxford,

OX3 4JX, UK

${ }^{\mathrm{e}}$ Highfield Adolescent Unit, Warneford Hospital,

Oxford Health NHS Foundation Trust

Oxford

OX3 7JX, UK. 
Corresponding author: Steven Marwaha

s.marwaha@warwick.ac.uk

Tel: 02476151046

Fax: 02476528375

\title{
Adult attention deficit hyperactivity symptoms and psychosis: epidemiological evidence from a population survey in England
}

\begin{abstract}
Despite both having some shared features, evidence linking psychosis and adult Attention Deficit Hyperactivity Disorder (ADHD) is sparse and inconsistent. Hypotheses tested were 1] adult ADHD symptoms are associated with auditory hallucinations, paranoid ideation and psychosis 2] links between ADHD symptoms and psychosis are mediated by prescribed ADHD medications, use of illicit drugs, and dysphoric mood. The Adult Psychiatric Morbidity Survey 2007 ( $N=7403)$ provided data for regression and multiple mediation analyses. ADHD symptoms were coded from the ADHD Self-Report Scale (ASRS). Higher ASRS total score was significantly associated with psychosis, paranoid ideation and auditory hallucinations despite controlling for socio-demographic variables, verbal IQ, autism spectrum disorder traits, childhood conduct problems, hypomanic and dysphoric mood. An ASRS score indicating probable ADHD diagnosis was also significantly associated with psychosis. The link between higher ADHD symptoms and psychosis, paranoia and auditory hallucinations was significantly mediated by dysphoric mood, but not by use of amphetamine, cocaine or cannabis. In conclusion, higher levels of adult ADHD symptoms and psychosis are linked and dysphoric mood may form part of the mechanism. Our analyses contradict the traditional clinical view that the main explanation for people with ADHD symptoms developing psychosis is illicit drugs.
\end{abstract}

Key words: ADHD, psychosis, cannabis, cocaine, depression 


\section{Introduction}

Attention Deficit Hyperactivity Disorder (ADHD) and schizophrenia have both been conceptualised as neurodevelopmental disorders (Owen et al., 2011). The defining symptoms of ADHD comprise inattention, hyperactivity and impulsivity, and are essentially neurodevelopmental arising in early childhood. There is significant persistence of symptoms from childhood to adulthood, with consequential social impairment (Barkley et al., 2002). In schizophrenia the defining symptoms of delusions, hallucinations and thought disorders commonly emerge in youth and in some patients are associated with neurocognitive and developmental deficits that precede these psychotic symptoms (Howes and Murray 2014). Given that neurocognitive features define the syndrome in ADHD, but are ancillary in psychosis, the question of the association between the two syndromes is empirical rather than definitional, and may have implications for the nature of both conditions and for mechanisms of symptom production.

So far, evidence for such an association has been sparse, inconsistent and tangential. Ross and colleagues (2006) reported that ADHD was the commonest comorbid condition in children and adolescents with schizophrenia (Ross et al., 2006). Young relatives of patients with schizophrenia have an increased rate of impulsivity, hyperactivity, attentional problems and emotional lability (Keshavan et al., 2003). Prospective studies of children with ADHD assessing the appearance of psychosis in adulthood are few in number and have led to mixed results. In a 10 year follow- up of 140 children diagnosed with ADHD, there was a trend level $(\mathrm{p}=0.057)$ increase in the hazard of developing psychosis (Biederman et al., 2006). Weiss and colleagues found no increased risk of psychosis in adulthood after 15 years in a small group of hyperactive children (Weiss et al., 1985). Most recently however, analysis of follow-up data from the Danish Psychiatric Register of over 200 children with ADHD suggests an increased relative risk (RR: 4.3) of schizophrenia in adulthood (Dalsgaard et al., 2013). 
There is a degree of overlap in the putative neuropsychological deficits in the two disorders. Attention deficits, which are part of the ADHD syndrome, are frequently identified in people with schizophrenia (Keshavan et al., 2003). Whilst neuropsychological deficits are generally associated with negative symptoms of schizophrenia, ability to sustain and select attention have also been strongly associated with positive schizotypal symptoms (Keefe et al., 1997) and positive symptoms in schizophrenia (Berman et al., 1997). Impulsivity in ADHD is thought to manifest at the motor level through hyperactivity (Rubia 2002). Much less is known about impulsivity in schizophrenia, though it is associated with comorbid substance use and aggression (Hoptman et al., 2010).

It is possible that links between ADHD and psychosis might be drug-related effects, whether through prescription or abuse. Psychostimulant use for ADHD in children can lead to visual or tactile hallucinations (Mosholder et al., 2009). The abuse of methylphenidate is known to cause psychotic-like symptoms in adults (Morton and Stockton 2000), an affect related to short term or chronic toxicity. Atomoxetine, the noradrenaline reuptake inhibitor prescribed for ADHD has been linked with paranoid delusions and mania-like states (Ross 2006), albeit rarely. In those with a pre-existing diagnosis of schizophrenia, the use of methylphenidate has been shown to worsen the condition (Ekinci and Sabuncuoglu 2011). People with ADHD are also more likely to consume illicit drugs known to increase the risk of psychosis, including cannabis (Faraone et al., 2007) and psycho-stimulants (McGough et al., 2005).

An alternative pathway between ADHD symptoms and psychosis might be provided by dysphoric mood. Anxiety and depression are strongly comorbid with ADHD (Kessler et al., 2006) occurring in $40-50 \%$ of adults with the condition, and may worsen the symptoms of ADHD (Schatz and Rostain 2006). Anxiety and depression have also been highlighted as significant factors in cognitive models of psychosis (Garety et al., 2001). They are associated with clinical and non-clinical paranoid thinking, and, alongside mood instability, with the emergence and persistence of psychosis (Freeman et al., 2013, Marwaha et al., 2014). Dysphoric mood may thus provide a mechanism common to both adult ADHD and psychosis. If so, the aetiology of affective disturbance may also be shared by both ADHD and psychosis, and this would include childhood adversities. Alternatively, the dysphoric or social consequences of one condition might drive the emergence of the other.

We used data from the Adult Psychiatric Morbidity Survey (APMS) 2007, a household survey conducted in England, to examine the relationship between ADHD symptoms and psychosis. 
We tested two hypotheses: 1] Adult ADHD symptoms will be associated with psychotic disorder, paranoid ideation and auditory hallucinations; 2] the association between ADHD symptoms and psychosis will be significantly mediated by prescribed ADHD medications, use of illicit drugs, and dysphoric mood.

\section{Methods}

\subsection{Setting and design}

Full details of the survey methods are available in the survey report (McManus et al., 2009). In brief, the sampling frame was the English Small Area Postcode Address File, and adults living in private households were selected using population-based multi-phase probability sampling. Experienced survey interviewers identified private households containing at least one person. They used the Kish grid method to select at random one person in each household, ensuring that all eligible household members had the same chance of being selected.

In order to render the results representative of the household population in the chosen age range, primary sampling units were stratified by region and socioeconomic characteristics. Thus in each case data were weighted to take account of survey design and non-response. The sample sizes were designed to have the statistical power required for estimating the prevalence of less common disorders (0.5\%-1.0\%) by age, sex and region. Survey interviewers carried out Phase 1 assessments using a detailed questionnaire that established socio-demographic characteristics, and covered a range of other topics. Screening procedures were applied to determine eligibility for the phase 2 interviews, which were carried out by clinically trained research interviewers.

\subsection{Measures}

\subsubsection{Dependent variable: Measures of psychosis}

Participants were screened during phase 1 for possible psychosis, a process that included the Psychosis Screening Questionnaire (PSQ) (Bebbington and Nayani 1995). The PSQ comprises items relating to hypomanic mood, thought interference, paranoid ideation, strange experiences, and auditory hallucinations. Participants were invited for a phase 2 assessment if 
they met one of the following criteria: currently on anti-psychotic medication; an inpatient stay for a mental or emotional problem in the past three months, or admission to a hospital or ward specialising in mental health problems at any time; a positive response to question $5 \mathrm{a}$ in the PSQ (this relates to auditory hallucinations); or a self-reported diagnosis of psychotic disorder or of symptoms suggestive of it. It was assumed that participants not meeting any of these criteria did not have psychosis.

A definitive diagnosis of psychosis was made in phase 2, and was based on the Schedules for Clinical Assessment in Neuropsychiatry (SCAN) system (WHO 1992), a semi-structured clinical interview that, with its attendant algorithm, provides ICD-10 diagnoses of psychotic disorder. In view of the expected low prevalence of psychotic disorders, a single category was created corresponding to ICD-10 codes F20-F29 and those F30 codes that require psychotic symptoms. However, in the analyses presented here, we used a measure of "probable psychosis". This category included SCAN positive cases, together with some participants who were not interviewed with SCAN. The latter were chosen because they met at least two of the phase 1 psychosis screening criteria listed above. The essential difference between the "psychotic disorder" and "probable psychosis" variables was that a positive diagnosis was only possible for 'psychotic disorder' if the respondent had a positive SCAN; while a positive diagnosis of 'probable psychosis' could also be made on the basis of responses to the phase one screening questions, where no SCAN interview was undertaken (McManus et al., 2009).

Paranoid ideas and auditory hallucinations were coded from items from the Psychosis Screening Questionnaire (PSQ), which asks questions in relation to the last year. Paranoid ideas were measured using 3 questions and auditory hallucinations using 2 questions. These were coded as ordinal variables with higher scores indicating greater severity, an approach for which there is some previous evidence of validity (Freeman et al., 2011). Persecutory ideation was assessed with PSQ questions 3 (“felt that people were against you in past year?"), 3a ("felt that people were deliberately acting to harm you/your interests?"), and 3b ("felt group of people was plotting to cause you serious harm?"). Hallucinatory experiences were assessed with PSQ questions 5 ("heard/saw things that other people couldn't?") and 5a ("heard voices saying quite a few words or sentences?"). 


\subsubsection{Independent variable: ADHD symptoms}

Adult ADHD symptoms were measured by a face to face interview using the ADHD SelfReport Scale (ASRS), an instrument that was developed in collaboration with the World Health Organisation (Adler et al., 2003). The six-item ASRS screen is a shortened version of the 18item Symptom Checklist scale measuring the frequency of recent DSM-IV Criterion A symptoms of adult ADHD. The screen is a reliable and valid measure (Kessler et al., 2007). There are 4 inattention and 2 hyperactivity-impulsivity items relating to the six months prior to interview. Respondents are asked to rate the frequency of these characteristics using a fivepoint response scale: 'never', 'rarely', 'sometimes', 'often' and 'very often'. The measure does not code the age of onset of the symptoms.

We used two measures of ADHD symptoms derived from the ASRS in this analysis. Firstly the total ASRS score as a continuous scale was used. In order to reduce the likelihood that any association between ADHD symptoms and psychosis could be attributed to the former being an epiphenomena of psychosis we also used a measure of probable adult ADHD diagnosis. A score of 4 or more on the screen has a sensitivity of $68.7 \%$ and specificity of $99.5 \%$ for a clinical syndrome classification (Kessler et al., 2005). A score of 4 can be assumed to be an overestimate of the prevalence of adult ADHD diagnosis and a score of 6 an underestimate (McManus et al., 2009). We conservatively used a score of 6 as a measure of probable adult ADHD diagnosis.

\subsubsection{Confounders}

IQ is linked to both ADHD symptoms and psychosis. In order to control for this confounding effect in the analyses we used estimated verbal IQ values derived from the results of the National Adult Reading Test (Nelson and O'Connell 1978).

Autistic spectrum disorder (ASD) traits were coded by the Autism-Spectrum Quotient-20 (ASQ-20)(Baron-Cohen et al., 2001). This is a brief self-report instrument designed to assess the extent to which adults of normal intelligence have ASD traits.

Because of the high levels of comorbidity between ADHD and externalizing disorders such as conduct disorder and in turn between these and psychosis we controlled for conduct problems before the age of 15 . Scores from the 15 items related to conduct problems in the Structured 
Clinical Interview for DSM-IV-II (SCID-II) were summed and then divided into six categories. These categories were endorsement of $0,1,2,3,4$ items and at least 5 items endorsed.

Hypomanic mood was assessed in relation to the past year in the first section of the PSQ and was adjusted for to ensure that any link between ADHD symptoms and psychosis was not simply a reflection of elated mood.

Adjustment was also made for dysphoric mood (depressive and anxiety symptoms) to counter the argument that the ADHD symptoms picked up by the ASRS reflect symptoms that occur in common mental disorders. These symptoms were assessed in phase I of the survey using the Clinical Interview Schedule Revised (CIS-R) (Lewis et al., 1992). This is an intervieweradministered structured schedule covering the week prior to interview. A continuous score is generated to indicate the extent of psychopathology. We used a binary CIS-R variable with a cut off of 12, which suggests significant psychopathology requiring a clinical assessment.

In addition to gender, we controlled for age, employment status, marital status, and ethnic grouping as these might be related to both dependent and independent variables. Participants were divided into categories of employed, unemployed and economically inactive. Marital status was coded as single, married/cohabiting, divorced/separated, and widowed. Participants were asked to allocate themselves to an ethnic group, using the same categories as the most recent UK Census. Because of the relatively small numbers in most groups, categories were collapsed into a black group vs the remainder.

\subsubsection{Mediators}

Participants in the survey were asked whether they were prescribed Methylphenidate (Ritalin) or Atomoxetine (no/ yes). Illicit use of amphetamine, cocaine, or cannabis in the last year was recorded in the survey and coded as no / yes.

Whilst depressive and anxiety symptoms were used as confounders in the regression analyses, we also wanted to test whether they might form part of the mechanism linking ADHD symptoms and psychosis. Therefore we used CIS-R score as a mediator of interest. 


\subsection{Analytic strategy}

Consistent with the wider literature, we assumed that ADHD symptoms, which start in childhood, precede psychosis, which usually begins in early adulthood. We use cross sectional data as a first approach to examining the association between ADHD symptoms and psychosis and potential mechanisms, given that this is a relatively new area.

We used Stata (version 13 for MAC) to analyse weighted survey data. To assess the association of level of ADHD symptoms and probable ADHD with identified psychosis, paranoid ideation and auditory hallucinations, we used binary logistic regression, or ordered logistic regression as appropriate in three sets of regression analyses. Each was carried out in 4 stages designed to be maximally informative in relation to our hypotheses. We initially produced unadjusted odds ratios. We next adjusted for socio-demographic characteristics (age, sex, marital status, employment status, and ethnicity). Verbal IQ, ASD traits and extent of conduct problems were then entered into the model. Finally we adjusted for the confounding effect of hypomanic mood and dysphoric mood (depressive and anxiety symptoms). If at any stage adjustment resulted in a loss of significant association $(p<0.05)$ we did not proceed further.

Next, we tested whether our measures of psychosis were associated with drugs (prescribed or illicit) that might explain any association between ADHD and psychotic phenomenon. Data on use of two medicines for ADHD were available in the dataset, methylphenidate (Ritalin) and atomoxetine. The unadjusted association between amphetamine, cocaine and cannabis use in the last year with psychosis were analysed using Chi square tests. If an association emerged we then tested the drugs role as a mediator linking ADHD symptoms and probable ADHD diagnosis with psychotic phenomenon. Following this, we tested whether dysphoric mood mediated any link between ADHD symptoms and probable ADHD and the 3 psychosis variables.

We applied the $-\mathrm{KHB}^{-}$(Karlson Holm Breen) command in Stata for these mediational analyses. This method decomposes the total effect of a variable into direct and indirect effects (Karlson et al., 2012). Confidence intervals are derived using the delta method. In these analyses, we controlled for the effects of confounders (IQ, ASD traits, conduct problems, hypomanic mood, socio-demographic variables) on the decomposition. Mediation analysis was only conducted for the associations between ADHD symptoms and probable ADHD, and the psychosis variables that were significant in our regression modelling. 


\section{Results}

The response rate of the survey was 57\%, and the age range of the 7403 respondents $16-95$ years. The spread of ADHD symptoms was: 0 (38.43\%), 1 (25.83\%), 2 (17.46\%), 3 (10.06\%), $4(5.36 \%), 5(2.30 \%)$ and $6(0.57 \%)$. The rates of each individual ADHD symptom are displayed in table 1 . There were 39 cases of people who scored 6 on the ASRS giving a prevalence of $0.53 \%$ for adult ADHD in this household survey. Other surveys have found prevalence rates of 2.9\% (Faraone and Biederman 2005) and 4.4\% (Kessler et al., 2006). This means that our sample of adults with an ASRS score of 6 were indeed likely to meet criteria for adult ADHD diagnosis. There were 27 cases of psychosis present in the last year diagnosed according to SCAN and 40 cases of probable psychosis (unweighted). On the basis of an ASRS score of 6 indicating ADHD the absolute numbers (unweighted) in each category were: no psychosis no ADHD: 7253, no psychosis ADHD: 35, psychosis no ADHD: 33, psychosis ADHD: 4. Weighted data Chi- squared test indicated $\mathrm{p}<0.0001$.

-Table 1 about here-

3.1 The association between ADHD symptoms (ASRS total score), probable ADHD and psychosis variables

The extent of adult ADHD symptoms was significantly associated with probable psychosis, paranoid ideation and auditory hallucinations (Table 2). When adjustment was made for socio demographic factors, verbal IQ, ASD traits, childhood conduct difficulties and, finally, hypomanic mood and dysphoric mood, the association was moderated. However, it remained statistically significant for all three response variables (all $\mathrm{p}<0.05$ ). Probable ADHD caseness was significantly associated with the psychosis variable after adjustment for the numerous confounders. It did not however remain significantly associated with paranoid thinking or auditory hallucinations specifically after adjustment. We completed post-hoc regression modelling using the ASRS cut off of 5 plus, the rationale being that this approximates to a prevalence of ADHD caseness of $2.87 \%$, similar to the figure of $2.9 \%$ found by Faroane and 
Biederman (Faraone and Biederman 2005). Using this ASRS cut off there was no significant association $(\mathrm{p}=0.469)$ between ADHD caseness and probable psychotic illness once adjustment was made for confounders. The adjusted associations between ASRS score 5 plus were significant with paranoid ideation $(\mathrm{p}=0.001)$ and auditory hallucinations $(\mathrm{p}=0.014)$.

-Table 2 about here-

\subsection{Mediational analyses}

Only 2 people (age 16 and over) in the survey mentioned taking Ritalin, with one of these scoring above the 4 cut off (normally used to indicate a clinical assessment is needed) in the ASRS. Only 1 person was taking Atomoxetine and they had an ASRS score of below 4. Further analyses of these particular variables were therefore inappropriate.

The weighted counts of people using cocaine, cannabis or amphetamines in the last year were 182.8, 549.2 and 54.4 respectively The illicit use of amphetamines in the last 12 months was significantly associated with paranoid ideation $(\mathrm{p}<0.001)$ but not with auditory hallucinations $(\mathrm{p}=0.29)$ or probable psychosis $(\mathrm{p}=0.17)$. Cocaine use was also only significantly associated with paranoid ideation $(\mathrm{p}<0.001)$, not with auditory hallucinations $(\mathrm{p}=0.26)$ or probable psychosis $(\mathrm{p}=0.07)$. Cannabis use in the last year was significantly associated with all three measures of psychosis: probable psychosis $(\mathrm{p}=0.049)$, paranoid ideation $(\mathrm{p}<0.001)$ and auditory hallucinations ( $\mathrm{p}<0.002$ ). In accord with our analysis plan, we carried out mediational analyses on the significant associations of individual drugs of abuse and measures of psychosis in this unadjusted analysis. No type of illicit drug use mediated the association between ASRS total score, and the psychosis variables. The results of these analyses are shown in table 3

-Table 3 about here-

In contrast dysphoric mood did mediate the link between ADHD symptoms and psychosis, paranoid ideation and auditory hallucinations. It explained 23\%, 23\% and $11 \%$ of the links 
respectively. Dysphoric mood explained $31 \%$ of the link between probable ADHD diagnosis and psychosis. The results of these mediational analyses are shown in table 4 .

-Table 4 about here-

\section{Discussion}

\subsection{Main findings}

We tested hypotheses regarding the association between the extent of ADHD symptoms, probable adult ADHD and psychosis, and examined potential underlying mechanisms. The main findings were that higher levels of ADHD symptoms in adults were associated with psychosis, paranoid ideation and auditory hallucinations. Probable ADHD caseness (ASRS = 6) is associated with probable psychosis only. This persisted even when we controlled for the confounding effects of IQ, childhood conduct problems, features of ASD and hypomanic and dysphoric mood, suggesting the association is robust, although fairly modest. Our post-hoc analyses using an ASRS score of 5 and above indicated that there was a significant association between ADHD caseness and paranoid ideation, and auditory hallucinations, but not with probable psychosis. This suggests it is only a high ADHD symptom load that is important in explaining the associations with a psychotic illness.

Very few adults with ADHD symptoms were taking prescribed drugs used in the treatment of ADHD such as Ritalin and Atomoxetine. This is an important clinical issue in its own right. We were not able to statistically test whether use of these medications is a significant mechanism underlying the link that was found. However at a population level the link exists even in the absence of the use of these medications. The association between ADHD symptoms, probable ADHD and psychosis, paranoia and auditory hallucinations is not mediated by the abuse of drugs such as amphetamines, cocaine or cannabis. We did however find that dysphoric mood is likely to form part of the pathway between higher ADHD symptom load in adults and psychosis. 


\subsection{Limitations}

We used a self-report assessment scale, the ASRS, to measure ADHD symptomatology and a probable diagnosis of ADHD. No clinical assessment incorporating diagnostic criteria and functional consequences of symptoms followed the administration of the screen and we therefore cannot be sure about a connection between diagnosed ADHD and psychosis. We did however use a cut off score of 6 on the ASRS to indicate probable ADHD diagnosis which appears to give a conservative estimate of clinical diagnosis. Never the less our findings should be considered preliminary. Attention deficit hyperactivity disorder is considered dimensional in nature, predisposing to a range of poor outcomes (Shah and Morton 2013); secondly, symptomatic persistence is greater than syndromal persistence of childhood ADHD into adulthood (Faraone et al., 2000). Both of these factors support our analytic approach and the utility of our findings, but further studies of diagnosed ADHD are needed in future research.

We decided to use the "probable psychosis" variable as opposed the "psychotic disorder" variable as coded by the SCAN. The main APMS report explains $75 \%$ of men and $59 \%$ of women meeting two or more psychosis screening criteria at phase one were assessed by SCAN as negative for psychosis. While psychotic disorder uses a weighting strategy, probable psychosis assigns an outcome according to phase one screening criteria. (McManus et al., 2009). It is also the case that some of the Screen Positive Scan Negative group are likely to be people with psychosis on medication and without current symptoms

Using the SCAN psychosis group, because of the smaller sample makes looking at the characteristics of this group problematic. The use of "probable psychosis" results in an entirely plausible prevalence of $0.5 \%$, which is quite close to the weighted prevalence of psychotic disorder obtained using the SCAN. The probable psychosis variable has been used in many and varied analyses (Bebbington et al., 2004, Brugha et al., 2004, Marwaha et al., 2014, Catone et al., 2015). Finally Qassem et al (Qassem et al., 2014) show the close correspondence in all demographic associations between "probable psychosis" and SCAN psychosis, based on amalgamated data from all three psychiatric morbidity surveys. For all these reasons, we, a priori decided to use the probable psychosis variable. 
Levels of psychotic symptoms as indexed by self-report measures administered in population surveys are very high and do not necessarily mean that a psychotic disorder is present (Kelleher et al., 2012). Our results should be interpreted in this context.

The numbers using amphetamines in the last year were relatively modest and therefore it is possible that we did not find an association between this use and auditory hallucinations or probable psychosis when one exists, though it seems unlikely that this would influence our main findings. The APMS is a cross sectional population survey, so inferences about causal directions and temporal precedence must be tentative. However, our analysis did not refute the possible role of affect in mediating the associations between extent of ADHD symptoms and psychotic phenomenon. It is possible that dysphoric mood is a severity indicator and further research using prospective data is required to confirm our findings.

\subsection{Implications}

This study is the first to use representative national survey data to test putative associations between ADHD and psychosis. It has been argued that major mental illnesses can be ordered based on the level of neurodevelopmental dysfunction, from intellectual disability at one pole, to autism, ADHD, schizophrenia and bipolar disorder (Owen et al., 2011). This hierarchy implies that the association between ADHD symptoms and psychosis might be specific. Alternatively given the risk of psychosis conferred by autistic spectrum disorder (Cheung et al., 2010), ADHD might form part of a common neurodevelopmental spectrum that predisposes to psychosis given a combination of psychosocial factors. However, our findings suggest a more specific association, given that the ADHD-psychosis link was robust after accounting for the effects of IQ and ASD.

A recent confirmatory factor analysis of psychopathology data from the Dunedin Multidisciplinary Health and Development study suggests that psychiatric disorders overlap to a large extent (Caspi et al., 2013) and might be categorized by a general psychopathology factor ( $\mathrm{p}$ factor), as well as internalizing and externalizing factors. One potential interpretation of our findings is therefore that ADHD symptoms and psychoses are simply overlapping constructs. However both disorders share a small but significant genetic vulnerability through rare 
chromosomal variants (Williams et al., 2010) as well as common single nucleotide polymorphisms (Hamshere et al., 2013).

The modest effect size in our population level analyses is consistent with this genetic evidence. It has been argued that the genetic architecture of ADHD shows a greater link with schizophrenia than with bipolar disorder (Hamshere et al., 2013), despite the strong body of evidence for comorbidity between ADHD and bipolar disorder (Wingo and Ghaemi 2007). How this genetic variation confers risk to both disorders is as yet unknown. The underlying shared biology may relate to the dopaminergic system with hyperactivity and hypoactivity in these systems in psychosis and ADHD (Levy and Swanson 2001) respectively. Reconciling these opposite findings in neuroimaging studies has led researchers to suggest that both disorders fall on a single continuum of dopaminergic imbalance (Barr 2001, Mehler-Wex et al., 2006).

Both those at risk of psychosis, and those who have already developed it, have impairments similar to those seen in ADHD in experimental tests of attention, and these may predict transition to first episode (Pukrop and Klosterkötter 2010). The precise mechanism by which impaired attention causes this risk is not clear; it may be as a vulnerability factor or by impacting on cognitive processes. Whilst it is not regarded as a core feature, patients with schizophrenia have been found to be more impulsive than controls using event-related functional magnetic resonance imaging (Kaladjian et al., 2011), and this impulsivity is especially associated with aggression (Hoptman et al., 2010). Our main results are consistent with this previous evidence.

The majority of children with ADHD will not have the syndrome in adolescence (Gau et al., 2010) or adulthood, and hyperactive-impulsive symptoms diminish with time at a greater rate than those of inattention (Biederman et al., 2000). This implies the link with psychosis may be a function of severity and persistence of ADHD symptoms into adulthood. In other words, those with a more serious form of the disorder have persisting symptoms, and form the main sub-population at higher risk of psychosis. In part, this last finding could be explicable by 
higher attention deficit and hyperactivity-impulsivity levels leading to a greater degree of aversive consequences over time, but we could not test for this specifically.

Factors associated with ADHD include peer victimization, abuse, social deprivation, and educational failure (Washbrook et al., 2013). These are also features of people with schizophrenia and those at risk of psychosis (Fisher et al., 2010). Both disorders therefore share common psychological and social risk factors. It is notable that many of these factors are also associated with dysphoric mood, which, we found forms part of the pathway between ADHD symptoms and psychotic phenomenon. Disentangling and understanding the relative effects of these risk factors and of anxiety and depression as well as other mediators, will require analyses of prospective longitudinal cohorts utilising structural equation modelling.

The association between ADHD symptoms and psychosis has treatment implications. There is under-treatment of ADHD in adults (Bolea-Alamañac et al., 2014), and this links to the very low ADHD medication use reported in this study. It is likely that this issue extends to the treatment of the syndrome when comorbid with psychosis. This is important, given that comorbidity with other psychiatric disorders worsens the outcome both for ADHD (Miller et al., 2007) and for psychosis (Sim et al., 2006). Given our findings, it is possible that treatment of ADHD might modify psychotic symptoms when the conditions are comorbid. In planning treatment, clinicians should not assume that the major reason for people with ADHD developing psychosis is illicit use of cocaine, amphetamine or cannabis. Our analyses directly contradict this view. Given the mediational link, it is important to treat anxiety and depression in adults with ADHD, not only to reduce the morbidity associated with these disorders, but also because this may afford some protection against psychosis and in particular paranoid thinking.

\section{Acknowledgements}

We would like to acknowledge the UK Data Archive and the National Centre for Social Research as the data collectors and depositors of the study. The National Centre for Social Research and the University of Leicester were the Principal Investigators of the Adult 
Psychiatric Morbidity Survey. They bear no responsibility for this further analysis or interpretation of this public dataset.

\section{Conflict of interest}

S.M has acted as an investigator in research commercially funded by Roche and Janssen-Cilag International. The other authors do not have any conflicts of interest to declare, financial or otherwise.

\section{Financial Acknowledgement}

A Medical Research Council Senior Clinical Fellowship supports DF. PB is emeritus; their respective universities or NHS Trusts employ the other authors. 


\section{References}

Adler, L., R. C. Kessler and T. Spencer (2003). Adult ADHD Self-Report Scale-v1. 1 (ASRS-v1. 1) Symptom Checklist. New York, NY: World Health Organization.

Barkley, R. A., M. Fischer, L. Smallish and K. Fletcher (2002). The persistence of attentiondeficit/hyperactivity disorder into young adulthood as a function of reporting source and definition of disorder. Journal of abnormal psychology. 111, 279-289.

Baron-Cohen, S., S. Wheelwright, R. Skinner, J. Martin and E. Clubley (2001). The autismspectrum quotient (AQ): Evidence from asperger syndrome/high-functioning autism, malesand females, scientists and mathematicians. Journal of autism and developmental disorders. 31, 5-17.

Barr, W. B. (2001). Schizophrenia and Attention Deficit Disorder. Annals of the New York Academy of Sciences. 931, 239-250.

Bebbington, P. and T. Nayani (1995). The psychosis screening questionnaire. International Journal of Methods in Psychiatric Research. 5, 11-20.

Bebbington, P. E., D. Bhugra, T. Brugha, N. Singleton, M. Farrell, R. Jenkins, G. Lewis and H. Meltzer (2004). Psychosis, victimisation and childhood disadvantage Evidence from the second British National Survey of Psychiatric Morbidity. The British Journal of Psychiatry. 185, 220-226.

Berman, I., B. Viegner, A. Merson, E. Allan, D. Pappas and A. I. Green (1997). Differential relationships between positive and negative symptoms and neuropsychological deficits in schizophrenia. Schizophrenia research. 25, 1-10.

Biederman, J., E. Mick and S. V. Faraone (2000). Age-dependent decline of symptoms of attention deficit hyperactivity disorder: impact of remission definition and symptom type. American journal of psychiatry. 157, 816-818.

Biederman, J., M. C. Monuteaux, E. Mick, T. Spencer, T. E. Wilens, J. M. Silva, L. E. Snyder and S. V. Faraone (2006). Young adult outcome of attention deficit hyperactivity disorder: a controlled 10-year follow-up study. Psychological medicine. 36, 167-180.

Bolea-Alamañac, B., D. J. Nutt, M. Adamou, P. Asherson, S. Bazire, D. Coghill, D. Heal, U. Müller, J. Nash and P. Santosh (2014). Evidence-based guidelines for the pharmacological management of attention deficit hyperactivity disorder: Update on recommendations from the British Association for Psychopharmacology. Journal of Psychopharmacology. 28, 179-203. Brugha, T. S., P. E. Bebbington, N. Singleton, D. Melzer, R. Jenkins, G. Lewis, M. Farrell, D. Bhugra, A. Lee and H. Meltzer (2004). Trends in service use and treatment for mental disorders in adults throughout Great Britain. The British Journal of Psychiatry. 185, 378-384. Caspi, A., R. M. Houts, D. W. Belsky, S. J. Goldman-Mellor, H. Harrington, S. Israel, M. H. Meier, S. Ramrakha, I. Shalev and R. Poulton (2013). The p Factor One General Psychopathology Factor in the Structure of Psychiatric Disorders? Clinical Psychological Science. 2, 119-137.

Catone, G., S. Marwaha, E. Kuipers, B. Lennox, D. Freeman, P. Bebbington and M. Broome (2015). Bullying victimisation and risk of psychotic phenomena: analyses of British national survey data. The Lancet Psychiatry.

Cheung, C., K. Yu, G. Fung, M. Leung, C. Wong, Q. Li, P. Sham, S. Chua and G. McAlonan (2010). Autistic disorders and schizophrenia: related or remote? An anatomical likelihood estimation. PloS one. 5, e12233.

Dalsgaard, S., P. B. Mortensen, M. Frydenberg, C. M. Maibing, M. Nordentoft and P. H. Thomsen (2013). Association between attention-deficit hyperactivity disorder in childhood and schizophrenia later in adulthood. European Psychiatry. 29, 259-263. 
Ekinci, O. and O. Sabuncuoglu (2011). Psychosis associated with switching from risperidone to aripiprazole in an adolescent on methylphenidate treatment. Progress in NeuroPsychopharmacology and Biological Psychiatry. 35, 648-649.

Faraone, S. V. and J. Biederman (2005). What is the prevalence of adult ADHD? Results of a population screen of 966 adults. Journal of Attention Disorders. 9, 384-391.

Faraone, S. V., J. Biederman, T. Spencer, T. Wilens, L. J. Seidman, E. Mick and A. E. Doyle (2000). Attention-deficit/hyperactivity disorder in adults: an overview. Biological psychiatry. 48, 9-20.

Faraone, S. V., T. E. Wilens, C. Petty, K. Antshel, T. Spencer and J. Biederman (2007).

Substance use among ADHD adults: implications of late onset and subthreshold diagnoses.

The American Journal on Addictions. 16, 24-34.

Fisher, H. L., P. B. Jones, P. Fearon, T. K. Craig, P. Dazzan, K. Morgan, G. Hutchinson, G. A. Doody, P. McGuffin and J. Leff (2010). The varying impact of type, timing and frequency of exposure to childhood adversity on its association with adult psychotic disorder.

Psychological medicine. 40, 1967-1978.

Freeman, D., G. Dunn, D. Fowler, P. Bebbington, E. Kuipers, R. Emsley, S. Jolley and P. Garety (2013). Current paranoid thinking in patients with delusions: the presence of cognitive-affective biases. Schizophrenia bulletin. 39, 1281-1287.

Freeman, D., S. McManus, T. Brugha, H. Meltzer, R. Jenkins and P. Bebbington (2011). Concomitants of paranoia in the general population. Psychological medicine. 41, 923-936. Garety, P., E. Kuipers, D. Fowler, D. Freeman and P. Bebbington (2001). A cognitive model of the positive symptoms of psychosis. Psychological medicine. 31, 189-196.

Gau, S. S.-F., Y.-J. Lin, A. T.-A. Cheng, Y.-N. Chiu, W.-C. Tsai and W.-T. Soong (2010). Psychopathology and symptom remission at adolescence among children with attentiondeficit-hyperactivity disorder. Australian and New Zealand Journal of Psychiatry. 44, 323332.

Hamshere, M. L., E. Stergiakouli, K. Langley, J. Martin, P. Holmans, L. Kent, M. J. Owen, M. Gill, A. Thapar, M. O'Donovan and N. Craddock (2013). A shared polygenic contribution between childhood ADHD and adult schizophrenia. The British Journal of Psychiatry. 203, 107-111.

Hoptman, M. J., D. D'Angelo, D. Catalano, C. J. Mauro, Z. E. Shehzad, A. C. Kelly, F. X. Castellanos, D. C. Javitt and M. P. Milham (2010). Amygdalofrontal functional disconnectivity and aggression in schizophrenia. Schizophrenia Bulletin. 36, 1020-1028. Howes, O. D. and R. M. Murray (2014). Schizophrenia: an integrated sociodevelopmentalcognitive model. The Lancet. 383, 10.

Kaladjian, A., R. Jeanningros, J. Azorin, J. Anton and P. Mazzola-Pomietto (2011). Impulsivity and neural correlates of response inhibition in schizophrenia. Psychological medicine. 41, 291-299.

Karlson, K. B., A. Holm and R. Breen (2012). Comparing Regression Coefficients Between Same-sample Nested Models Using Logit and Probit A New Method. Sociological methodology. 42, 286-313.

Keefe, R. S., J. M. Silverman, R. C. Mohs, L. J. Siever, P. D. Harvey, L. Friedman, S. E. Lees Roitman, R. L. DuPre, C. J. Smith and J. Schmeidler (1997). Eye tracking, attention, and schizotypal symptoms in nonpsychotic relatives of patients with schizophrenia. Archives of general psychiatry. 54, 169-176.

Kelleher, I., D. Connor, M. C. Clarke, N. Devlin, M. Harley and M. Cannon (2012).

Prevalence of psychotic symptoms in childhood and adolescence: a systematic review and meta-analysis of population-based studies. Psychological medicine. 42, 1857-1863. 
Keshavan, M. S., M. Sujata, A. Mehra, D. M. Montrose and J. A. Sweeney (2003). Psychosis proneness and ADHD in young relatives of schizophrenia patients. Schizophrenia research. $59,85-92$.

Kessler, R. C., L. Adler, M. Ames, O. Demler, S. Faraone, E. Hiripi, M. J. Howes, R. Jin, K. Secnik and T. Spencer (2005). The World Health Organization Adult ADHD Self-Report Scale (ASRS): a short screening scale for use in the general population. Psychological medicine. 35, 245-256.

Kessler, R. C., L. Adler, R. Barkley, J. Biederman, C. K. Conners, O. Demler, S. V. Faraone, L. L. Greenhill, M. J. Howes and K. Secnik (2006). The prevalence and correlates of adult ADHD in the United States: results from the National Comorbidity Survey Replication. The American journal of psychiatry. 163, 716-723.

Kessler, R. C., L. A. Adler, M. J. Gruber, C. A. Sarawate, T. Spencer and D. L. Van Brunt (2007). Validity of the World Health Organization Adult ADHD Self - Report Scale (ASRS) Screener in a representative sample of health plan members. International journal of methods in psychiatric research. 16, 52-65.

Levy, F. and J. M. Swanson (2001). Timing, space and ADHD: the dopamine theory revisited. Australian and New Zealand Journal of Psychiatry. 35, 504-511.

Lewis, G., A. J. Pelosi, R. Araya and G. Dunn (1992). Measuring psychiatric disorder in the community: a standardized assessment for use by lay interviewers. Psychological medicine. 22, 465-486.

Marwaha, S., M. R. Broome, P. E. Bebbington, E. Kuipers and D. Freeman (2014). Mood instability and psychosis: analyses of British national survey data. Schizophrenia bulletin. 40, 9.

McGough, J. J., S. L. Smalley, J. T. McCracken, M. Yang, M. Del'Homme, D. E. Lynn and S. Loo (2005). Psychiatric comorbidity in adult attention deficit hyperactivity disorder: findings from multiplex families. American Journal of Psychiatry. 162, 1621-1627.

McManus, S., H. Meltzer, T. S. Brugha, P. E. Bebbington and R. Jenkins (2009). Adult Psychiatric Morbidity in England, 2007: Results of a Household Survey. London, The NHS Information Centre for Health and Social Care.

Mehler-Wex, C., P. Riederer and M. Gerlach (2006). Dopaminergic dysbalance in distinct basal ganglia neurocircuits: implications for the pathophysiology of Parkinson's disease, schizophrenia and attention deficit hyperactivity disorder. Neurotoxicity research. 10, 167179.

Miller, T. W., J. T. Nigg and S. V. Faraone (2007). Axis I and II comorbidity in adults with ADHD. Journal of abnormal psychology. 116, 519-528.

Morton, W. A. and G. G. Stockton (2000). Methylphenidate abuse and psychiatric side effects. Primary care companion to the Journal of clinical psychiatry. 2, 159-164.

Mosholder, A. D., K. Gelperin, T. A. Hammad, K. Phelan and R. Johann-Liang (2009).

Hallucinations and Other Psychotic Symptoms Associated With the Use of Attention-

Deficit/Hyperactivity Disorder Drugs in Children. Pediatrics. 123, 611-616.

Nelson, H. E. and A. O'Connell (1978). Dementia: the estimation of premorbid intelligence levels using the New Adult Reading Test. Cortex. 14, 234-244.

Owen, M. J., M. C. O’Donovan, A. Thapar and N. Craddock (2011). Neurodevelopmental hypothesis of schizophrenia. The British Journal of Psychiatry. 198, 173-175.

Pukrop, R. and J. Klosterkötter (2010). Neurocognitive indicators of clinical high-risk states for psychosis: a critical review of the evidence. Neurotoxicity research. 18, 272-286.

Qassem, T., P. Bebbington, N. Spiers, S. McManus, R. Jenkins and S. Dein (2014).

Prevalence of psychosis in black ethnic minorities in Britain: analysis based on three national surveys. Social psychiatry and psychiatric epidemiology. 1-8. 
Ross, R. (2006). Psychotic and manic-like symptoms during stimulant treatment of attention deficit hyperactivity disorder. American Journal of Psychiatry. 163, 1149-1152.

Ross, R. G., S. Heinlein and H. Tregellas (2006). High rates of comorbidity are found in childhood-onset schizophrenia. Schizophrenia research. 88, 90-95.

Rubia, K. (2002). The dynamic approach to neurodevelopmental psychiatric disorders: use of fMRI combined with neuropsychology to elucidate the dynamics of psychiatric disorders, exemplified in ADHD and schizophrenia. Behavioural brain research. 130, 47-56.

Schatz, D. B. and A. L. Rostain (2006). ADHD With Comorbid Anxiety A Review of the Current Literature. Journal of Attention Disorders. 10, 141-149.

Shah, P. J. and M. J. S. Morton (2013). Adults with attention-deficit hyperactivity disorder diagnosis or normality? The British Journal of Psychiatry. 203, 317-319.

Sim, K., T. H. Chua, Y. H. Chan, R. Mahendran and S. A. Chong (2006). Psychiatric comorbidity in first episode schizophrenia: a 2 year, longitudinal outcome study. Journal of psychiatric research. 40, 656-663.

Washbrook, E., C. Propper and K. Sayal (2013). Pre-school hyperactivity/attention problems and educational outcomes in adolescence: prospective longitudinal study. The British Journal of Psychiatry. 203, 265-271.

Weiss, G., L. Hechtman, T. Milroy and T. Perlman (1985). Psychiatric status of hyperactives as adults: a controlled prospective 15-year follow-up of 63 hyperactive children. Journal of the American Academy of Child Psychiatry. 24, 211-220.

WHO (1992). SCAN: Schedules for Clinical Assessment in Neuropsychiatry. Geneva, WHO. Williams, N. M., I. Zaharieva, A. Martin, K. Langley, K. Mantripragada, R. Fossdal, H.

Stefansson, K. Stefansson, P. Magnusson, O. O. Gudmundsson, O. Gustafsson, P. Holmans, M. J. Owen, M. O'Donovan and A. Thapar (2010). Rare chromosomal deletions and duplications in attention-deficit hyperactivity disorder: a genome-wide analysis. The Lancet. 376, 1401-1408.

Wingo, A. P. and S. N. Ghaemi (2007). A systematic review of rates and diagnostic validity of comorbid adult attention-deficit/hyperactivity disorder and bipolar disorder. Journal of Clinical Psychiatry. 1776-1786. 
Table 1: Responses (\%) to individual ASRS questions (weighted)

\begin{tabular}{|c|c|c|c|c|c|c|}
\hline & \multicolumn{6}{|c|}{ Adult ADHD self report scale } \\
\hline & $\begin{array}{c}\text { "How often do you } \\
\text { have trouble } \\
\text { wrapping up the fine } \\
\text { details of a project } \\
\text { once the challenging } \\
\text { parts have been } \\
\text { done?" } \\
\%\end{array}$ & $\begin{array}{c}\text { How often do you } \\
\text { have difficulty } \\
\text { getting things in } \\
\text { order when you } \\
\text { have to do a task } \\
\text { that requires } \\
\text { organization? } \\
\%\end{array}$ & $\begin{array}{l}\text { How often to do } \\
\text { you have problems } \\
\text { remembering } \\
\text { appointments or } \\
\text { obligations } \\
\%\end{array}$ & $\begin{array}{c}\text { When you have a } \\
\text { task that requires a } \\
\text { lot of thought, how } \\
\text { often do you avoid } \\
\text { or delay getting } \\
\text { started? } \\
\%\end{array}$ & $\begin{array}{c}\text { How often do you } \\
\text { fidget or squirm } \\
\text { with your hands or } \\
\text { your feet when you } \\
\text { have to sit down } \\
\text { for a long time? } \\
\%\end{array}$ & $\begin{array}{c}\text { How often do you } \\
\text { feel overly active } \\
\text { and compelled to } \\
\text { do things, like you } \\
\text { were driven by a } \\
\text { motor? } \\
\%\end{array}$ \\
\hline Never & 42.69 & 45.16 & 38.43 & 30.19 & 32.76 & 39.24 \\
\hline Rarely & 29.79 & 33.5 & 32.6 & 28.12 & 20.75 & 25.57 \\
\hline Sometimes & 19.89 & 16.11 & 20.1 & 29.58 & 21.71 & 22.28 \\
\hline Often & 5.78 & 3.96 & 6.38 & 9.41 & 16.13 & 9.52 \\
\hline Very often & 1.85 & 1.26 & 2.48 & 2.71 & 8.66 & 3.39 \\
\hline $\begin{array}{c}\% \text { with responses } \\
\text { indicating symptom } \\
\text { is significant* }\end{array}$ & 27.52 & 21.33 & 28.96 & 12.12 & 24.79 & 12.91 \\
\hline
\end{tabular}

*symptom significance as indicated by previously used cut-offs (McManus et al., 2009) 
Table 2: The cross-sectional association between ADHD symptoms and psychosis and psychotic symptoms

\begin{tabular}{|c|c|c|c|c|c|c|}
\hline & \multicolumn{3}{|c|}{ ASRS continuous score } & \multicolumn{3}{|c|}{ ASRS score $=6$} \\
\hline \multicolumn{7}{|c|}{ Probable psychosis } \\
\hline & $\begin{array}{l}\text { Odds ratio } \\
\text { (95\% } \\
\text { confidence } \\
\text { limits) }\end{array}$ & $\mathrm{t}$ & $\mathrm{p}>\mathrm{t}$ & $\begin{array}{l}\text { Odds ratio } \\
(95 \% \\
\text { confidence } \\
\text { limits) }\end{array}$ & $\mathrm{t}$ & $\mathrm{p}>\mathrm{t}$ \\
\hline Unadjusted & $\begin{array}{l}1.31(1.22- \\
1.41)\end{array}$ & 7.22 & $<0.001$ & $\begin{array}{c}29.28(8.10- \\
105.83)\end{array}$ & 5.17 & $<0.001$ \\
\hline $\begin{array}{l}\text { Controlling for } \\
\text { socio- } \\
\text { demographic } \\
\text { variables }{ }^{1}\end{array}$ & $\begin{array}{l}1.28(1.19- \\
1.38)\end{array}$ & 6.41 & $<0.001$ & $\begin{array}{c}16.59(4.52- \\
60.85)\end{array}$ & 4.26 & $<0.001$ \\
\hline $\begin{array}{l}\text { Controlling for } \\
\text { the above plus } \\
\text { estimated verbal } \\
\text { IQ, ASD score } \\
\text { and conduct } \\
\text { problems score }\end{array}$ & $\begin{array}{l}1.19(1.10- \\
1.29)\end{array}$ & 4.42 & $<0.001$ & $\begin{array}{l}6.76(1.56- \\
29.33)\end{array}$ & 2.46 & 0.011 \\
\hline $\begin{array}{l}\text { Controlling for } \\
\text { the above plus } \\
\text { hypomanic and } \\
\text { dysphoric mood }\end{array}$ & $\begin{array}{l}1.12(1.04- \\
1.22)\end{array}$ & 2.85 & 0.005 & $\begin{array}{c}.25(1.06- \\
16.95)\end{array}$ & 2.06 & 0.041 \\
\hline \multicolumn{7}{|c|}{ Paranoid ideation } \\
\hline & $\begin{array}{c}\text { Odds ratio } \\
(95 \% \\
\text { confidence } \\
\text { limits })\end{array}$ & $\mathrm{t}$ & $\mathrm{p}>\mathrm{t}$ & $\begin{array}{l}\text { Odds ratio } \\
(95 \% \\
\text { confidence } \\
\text { limits }) \\
\end{array}$ & $\mathrm{t}$ & $\mathrm{p}>\mathrm{t}$ \\
\hline Unadjusted & $\begin{array}{l}1.22(1.20- \\
1.24)\end{array}$ & 23.50 & $<0.001$ & $\begin{array}{c}5.56(3.02- \\
10.24) \\
\end{array}$ & 5.54 & $<0.001$ \\
\hline $\begin{array}{l}\text { Controlling for } \\
\text { socio- } \\
\text { demographic } \\
\text { variables }{ }^{1}\end{array}$ & $\begin{array}{l}1.20(1.18- \\
1.23)\end{array}$ & 20.29 & $<0.001$ & $\begin{array}{c}4.94(2.60- \\
9.40)\end{array}$ & 4.90 & $<0.001$ \\
\hline $\begin{array}{l}\text { Controlling for } \\
\text { the above plus } \\
\text { estimated verbal } \\
\text { IQ, ASD score } \\
\text { and conduct } \\
\text { problems score }\end{array}$ & $\begin{array}{c}1.17(1.14- \\
1.19)\end{array}$ & 16.36 & $<0.001$ & $\begin{array}{l}2.98(1.58- \\
6.01)\end{array}$ & 3.08 & 0.002 \\
\hline $\begin{array}{l}\text { Controlling for } \\
\text { the above plus }\end{array}$ & $\begin{array}{c}1.12(1.10- \\
1.14)\end{array}$ & 11.13 & $<0.001$ & $\begin{array}{l}1.61(0.86- \\
3.00)\end{array}$ & 1.51 & 0.133 \\
\hline
\end{tabular}




\begin{tabular}{|c|c|c|c|c|c|c|}
\hline $\begin{array}{l}\text { hypomanic and } \\
\text { dysphoric mood }\end{array}$ & & & & & & \\
\hline \multicolumn{7}{|c|}{ Auditory hallucinations } \\
\hline & $\begin{array}{l}\text { Odds ratio } \\
(95 \% \\
\text { confidence } \\
\text { limits) }\end{array}$ & $\mathrm{t}$ & $\mathrm{p}>\mathrm{t}$ & $\begin{array}{l}\text { Odds ratio } \\
\quad(95 \% \\
\text { confidence } \\
\text { limits }) \\
\end{array}$ & $\mathrm{t}$ & $\mathrm{p}>\mathrm{t}$ \\
\hline Unadjusted & $\begin{array}{c}1.19(1.16- \\
1.23)\end{array}$ & 12.40 & $<0.001$ & $\begin{array}{c}3.18(1.04- \\
9.71)\end{array}$ & 2.04 & 0.043 \\
\hline $\begin{array}{l}\text { Controlling for } \\
\text { socio- } \\
\text { demographic } \\
\text { variables } 1\end{array}$ & $\begin{array}{c}1.18(1.15- \\
1.21)\end{array}$ & 11.94 & $<0.001$ & $\begin{array}{c}2.55(0.83- \\
7.85)\end{array}$ & 1.64 & 0.102 \\
\hline $\begin{array}{l}\text { Controlling for } \\
\text { the above plus } \\
\text { estimated verbal } \\
\text { IQ, ASD score } \\
\text { and conduct } \\
\text { problems score }\end{array}$ & $\begin{array}{c}1.14(1.10- \\
1.18)\end{array}$ & 8.18 & $<0.001$ & $* * *$ & $* * *$ & $* * *$ \\
\hline $\begin{array}{l}\text { Controlling for } \\
\text { the above plus } \\
\text { hypomanic and } \\
\text { dysphoric mood }\end{array}$ & $\begin{array}{c}1.11(1.08- \\
1.15)\end{array}$ & 6.45 & $<0.001$ & $* * *$ & $* * *$ & $* * *$ \\
\hline
\end{tabular}

${ }^{1}$ age, sex, marital status, employment status and ethnicity 
Table 3: Illicit drug use as mediators of the link between the ADHD symptoms and psychotic phenomenon in adults

\begin{tabular}{|c|c|c|c|c|c|}
\hline \multicolumn{6}{|c|}{ Amphetamine use } \\
\hline \multicolumn{6}{|c|}{ Paranoid ideation } \\
\hline Effect & OR & $\begin{array}{c}\text { Robust } \\
\text { standard } \\
\text { error }\end{array}$ & $\mathrm{Z}$ & $\mathrm{P}>\mathrm{Z}$ & $95 \% \mathrm{CI}$ \\
\hline Total & 1.16 & 0.01 & 15.18 & $<0.001$ & $1.14-1.18$ \\
\hline Direct & 1.16 & 0.01 & 15.18 & $<0.001$ & $1.03-1.19$ \\
\hline Indirect & 1.00 & 0.0002 & 1.08 & 0.279 & $1.00-1.00$ \\
\hline \multicolumn{6}{|c|}{ Cocaine use } \\
\hline \multicolumn{6}{|c|}{ Paranoid ideation } \\
\hline Effect & OR & $\begin{array}{c}\text { Robust } \\
\text { standard } \\
\text { error }\end{array}$ & $\mathrm{Z}$ & $\mathrm{P}>\mathrm{Z}$ & $95 \% \mathrm{CI}$ \\
\hline Total & 1.16 & 0.01 & 15.56 & $<0.001$ & 1.14-1.19 \\
\hline Direct & 1.16 & 0.01 & 15.55 & $<0.001$ & $1.14-1.86$ \\
\hline Indirect & 1.00 & 0.0001 & 0.00 & 0.996 & $1.00-1.00$ \\
\hline \multicolumn{6}{|c|}{ Cannabis use } \\
\hline \multicolumn{6}{|c|}{ Probable psychosis (ASRS continuous score) } \\
\hline Effect & OR & $\begin{array}{c}\text { Robust } \\
\text { standard } \\
\text { error }\end{array}$ & $\mathrm{Z}$ & $\mathrm{P}>\mathrm{Z}$ & $95 \% \mathrm{CI}$ \\
\hline Total & 1.18 & 0.04 & 4.55 & $<0.001$ & $1.10-1.27$ \\
\hline Direct & 1.18 & 0.04 & 4.58 & $<0.001$ & $1.10-1.26$ \\
\hline Indirect & 1.00 & 0.003 & 0.52 & 0.602 & $1.00-1.00$ \\
\hline \multicolumn{6}{|c|}{ Probable psychosis (ASRS score $=6)$} \\
\hline Total & 5.96 & 3.76 & 2.82 & 0.005 & $1.73-20.54$ \\
\hline Direct & 5.87 & 3.69 & 2.81 & 0.005 & $1.71-20.16$ \\
\hline Indirect & 1.01 & 0.04 & 0.36 & 0.718 & $0.94-1.09$ \\
\hline \multicolumn{6}{|c|}{ Paranoid ideation } \\
\hline Effect & OR & $\begin{array}{c}\text { Robust } \\
\text { standard } \\
\text { error }\end{array}$ & $\mathrm{Z}$ & $\mathrm{P}>\mathrm{Z}$ & $95 \% \mathrm{CI}$ \\
\hline Total & 1.16 & 0.01 & 15.46 & $<0.001$ & $1.14-1.19$ \\
\hline Direct & 1.16 & 0.01 & 15.24 & $<0.001$ & $1.14-1.18$ \\
\hline Indirect & 1.00 & 0.0007 & 1.35 & 0.177 & $1.00-1.00$ \\
\hline \multicolumn{6}{|c|}{ Auditory hallucination } \\
\hline Effect & OR & $\begin{array}{c}\text { Robust } \\
\text { standard } \\
\text { error } \\
\end{array}$ & $\mathrm{Z}$ & $\mathrm{P}>\mathrm{Z}$ & $95 \% \mathrm{CI}$ \\
\hline Total & 1.14 & 0.02 & 7.39 & $<0.001$ & $1.10-1.18$ \\
\hline Direct & 1.14 & 0.02 & 7.35 & $<0.001$ & $1.10-1.18$ \\
\hline Indirect & 1.00 & 0.001 & 0.05 & 0.958 & $1.00-1.00$ \\
\hline
\end{tabular}


Table 4: Dysphoric mood (depression and anxiety) as a mediator of the link between ADHD symptoms and psychotic phenomena in adults

\begin{tabular}{|c|c|c|c|c|c|}
\hline \multicolumn{6}{|c|}{ Dysphoric mood } \\
\hline \multicolumn{6}{|c|}{ Probable psychosis (ASRS continuous score) } \\
\hline Effect & OR & $\begin{array}{c}\text { Robust } \\
\text { standard } \\
\text { error }\end{array}$ & $\mathrm{Z}$ & $\mathrm{P}>\mathrm{Z}$ & $95 \% \mathrm{CI}$ \\
\hline Total & 1.16 & 0.04 & 4.18 & $<0.001$ & $1.08-1.25$ \\
\hline Direct & 1.12 & 0.04 & 3.16 & 0.002 & $1.04-1.21$ \\
\hline Indirect & 1.03 & 0.01 & 3.34 & $0.001^{*}$ & $1.01-1.06$ \\
\hline \multicolumn{6}{|c|}{$22.93 \%$ of the link mediated } \\
\hline \multicolumn{6}{|c|}{ Probable psychosis (ASRS score $=6)$} \\
\hline Total & 8.14 & 4.95 & 3.45 & 0.001 & $2.47-26.80$ \\
\hline Direct & 4.25 & 2.49 & 2.47 & 0.014 & $1.35-13.39$ \\
\hline Indirect & 1.91 & 0.43 & 2.93 & 0.003 & $1.24-2.96$ \\
\hline \multicolumn{6}{|c|}{$31.04 \%$ of the link mediated } \\
\hline \multicolumn{6}{|c|}{ Paranoid ideation } \\
\hline Effect & OR & $\begin{array}{l}\text { Robust } \\
\text { standard } \\
\text { error }\end{array}$ & $\mathrm{Z}$ & $\mathrm{P}>\mathrm{Z}$ & $95 \% \mathrm{CI}$ \\
\hline Total & 1.16 & 0.01 & 14.69 & $<0.001$ & $1.13-1.18$ \\
\hline Direct & 1.12 & 0.01 & 10.94 & $<0.001$ & $1.10-1.14$ \\
\hline Indirect & 1.03 & 0.003 & 11.07 & $<0.001^{*}$ & $1.03-1.04$ \\
\hline \multicolumn{6}{|c|}{$22.90 \%$ of the link mediated } \\
\hline \multicolumn{6}{|c|}{ Auditory hallucination } \\
\hline Effect & OR & $\begin{array}{c}\text { Robust } \\
\text { standard } \\
\text { error }\end{array}$ & $\bar{Z}$ & $\mathrm{P}>\mathrm{Z}$ & $95 \% \mathrm{CI}$ \\
\hline Total & 1.13 & 0.02 & 7.13 & $<0.001$ & $1.09-1.17$ \\
\hline Direct & 1.11 & 0.02 & 6.04 & $<0.001$ & $1.08-1.16$ \\
\hline Indirect & 1.01 & 0.004 & 3.10 & $0.002^{*}$ & $1.00-1.02$ \\
\hline
\end{tabular}

*indicates dysphoric mood as a significant mediator after controlling for socio-demographic variables, verbal IQ, ASD traits, childhood conduct problems and hypomanic mood 